\title{
Autopsy Findings in a Case of Acute Paraquat Poisoning with Extensive Cerebral Purpura
}

\author{
Takeo Mukada, Nobuaki Sasano and Kozo Sato* \\ The Second Department of Pathology, Tohoku University School \\ of Medicine and *Department of Internal Medicine, Sendai \\ Red Cross Hospital, Sendai 980
}

\begin{abstract}
Mukada, T., Sasano N. and Sato K. Autopsy Findings in a Case of Acute Paraquat Poisoning with Extensive Cerebral Purpura. Tohoku J. exp. Med., 1978, 125 (3), 253-263 - An autopsy case of paraquat poisoning in an adult male died on the 6th day of intoxication was presented. Histological and electron microscopic observations demonstrated interstitial pneumonia with distinct interstitial fibrosis and the initial stage of alveolar fibrosis with coexisting edema and hyaline membrane formation. Striking hemorrhagic leukoencephalopathy, i.e. 'purpura cerebri,' was noted throughout the central nervous system involving almost exclusively the white matter. It consisted of focal hemorrhages of various stages accompanied by demyelinating processes of various extent. Globular and/or amorphous proteinaceous materials of uncertain nature were demonstrated in the vascular lumina throughout the brain. - cerebral purpura; paraquat poisoning; pulmonary fibrosis; autopsy
\end{abstract}

Paraquat (Gramoxone ${ }^{\circledR}$ ), one of the widely used herbicides, is known to cause peculiar lesions in the human and animal lungs and to have a systemic toxicity as well. Many autopsy records of paraquat poisoning ever reported have elucidated a life threatening progressive pulmonary fibrosis resulting, sooner or later, in severe respiratory failure (Matthew et al. 1968; Borchard et al. 1974; Poche 1974). The present case report dealing with autopsy findings of acute paraquat poisoning manifesting the characteristic pulmonary lesions was provided to link consecutive pathological features of fibrosis of the paraquat lung. Extensive involvement of the central nervous system by hemorrhagic leukoencephalopathy is emphasized as a lesion rarely described in the literature.

\section{Case Report}

Clinical course. A man aged 44 years ingested paraquat (Gramoxone ${ }^{\circledR}$ ) by accident. The amount of poison estimated was 2 to $3 \mathrm{ml} \mathrm{of} 20 \%$ concentrated solution. No severe symptom was noted during the first 3 days cared by a physician.

He was admitted to a hospital for severe illness with nausea, dysphagia, jaundice and oliguria on the 5th day of intoxication. Dyspnea, marked irritability and restlessness appeared and peritoneal dialysis was unsuccessful. A chest x-ray

Received for publication, December 5, 1977. 
TABLE 1. The laboratory data*

\begin{tabular}{cl}
\hline Blood & \\
$\mathrm{pH}$ & 7.238 \\
$\mathrm{P}_{\mathrm{O} 2}$ & $46 \mathrm{mmHg}$ \\
$\mathrm{P}_{\text {CO2 }}$ & $28.5 \mathrm{mmHg}$ \\
Bicarbonate & $13.8 \mathrm{mEq} /$ liter \\
Base excess & $-14.3 \mathrm{mEq} /$ liter \\
BUM & $134.9 \mathrm{mg} / 100 \mathrm{ml}$ \\
NPN & $160.6 \mathrm{mg} / 100 \mathrm{ml}$ \\
GOT & 138 units \\
GPT & 138 units \\
Al.Pase & 28.7 units \\
LAP & 573 units \\
LDH & 283 units \\
RBC & $442 \times 10^{4} / \mathrm{mm}^{3}$ \\
WBC & $8900 / \mathrm{mm}^{3}$ \\
Ht & $38 \%$ \\
Sahli & $78 \%$ \\
Urine & \\
Protein & $( \pm)$ \\
Sugar & $( \pm)$ \\
RBC & $3 /$ field \\
\hline
\end{tabular}

* Obtained on the 5 th day of poisoning.

film taken on the 6th day of intoxication revealed diffuse and dense reticular shadows, especially pronounced in the right lung field. The patient died on the 2nd hospital day, i.e. the 6th day of intoxication, after $\mathrm{O}_{2}$ inhalation for $20 \mathrm{hr}$. Selected laboratory data are shown in Table 1.

Autopsy findings. Autopsy carried out one hr postmortal revealed a well nourished man with slight to moderate jaundice. The voluminous lungs, weighing $850 \mathrm{~g}$ in right and $740 \mathrm{~g}$ in left, showed fibrotic tough consistency with focal hemorrhage and rather tenacious edema (Fig. 1). The cut surface was glassy in appearance before fixation.

The brain weighing $1470 \mathrm{~g}$ was edematous and had purpuric hemorrhage extensively involving the cerebrum, brain stem, cerebellum, and the spinal cord. The distribution of hemorrbagic foci, up to $5 \mathrm{~mm}$ in the largest diameter, was mostly confined to the white matter (Fig. 2). No apparent lesion was observed in major arteries or veins or sinuses of the brain.

Acute corrosive glossitis, pharyngo-laryngo-esophagitis, and gastritis with ulcers and numerous erosions were evident. The liver was icteric and moderately enlarged. The kidneys showed moderate swelling with anemic cortices. Slight myocardial hypertrophy was observed in bilateral ventricles.

Histopathological findings. The findings are shown in Figs. 3-8. Pulmonary fibrosis was mostly confined to the alveolar walls which were thickened with prominent inflammatory cell infiltration, fibroblastic cell proliferation and 


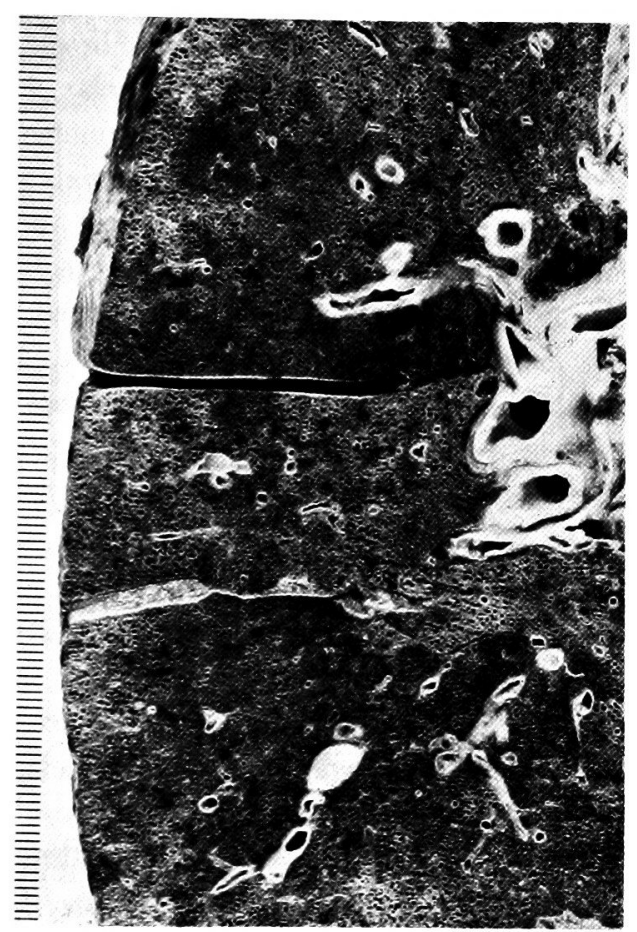

Fig. 1. Fibrotic and solid lung after fixation. Note the expanded peripheral air spaces and mottled appearance with focal hemorrhage. Some bronchi were plugged with mucus. The pleural surface was intact but for focal hemorrhage.

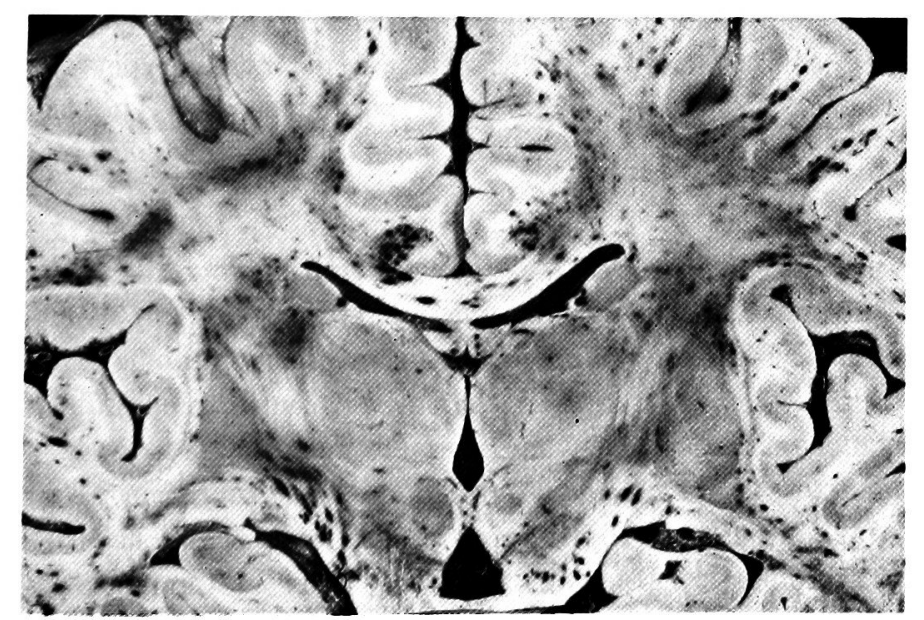

Fig. 2. A frontal section of the brain through the red nucleus. Note the widespread and rather symmetrically distributed purpuric foci confined mainly to the white matter. 
capillary engorgement. Thickened septa were sometimes composed of two or more sheets of alveolar walls fused by collapse. Alveolar fibrosis, only minimal or of initial stage, was also observed. Exudation into alveolar spaces revealed membranous and/or clumped hyaline materials other than homogeneous edema fluid and focal fibrin deposit. Organization of hyaline materials was not apparent. Extravasated red blood corpuscles were present in various amounts throughout the air spaces. Pneumocyte shedding and activation of alveolar macrophages were common. Plumped alveolar epithelial cells were observed though rarely, but distinct proliferation of epithelial cells of the terminal bronchioles was not recognized. Thickening of the alveolar walls was sometimes remarkable, and air spaces, especially those of terminal bronchioles and alveolar ducts, were expanded. But the basic structure of alveolar framework was mostly preserved. All these pathological changes were fairly evenly distributed in all lobes of the bilateral lungs. The bronchi and bronchioles were well preserved.

Lesions of purpuric hemorrhage almost unexceptionally distributed in the white matter of the brain involved nerve fibers distorted and disintegrated to various extent. Glial proliferation was scarce if not excluded. Degenerative changes were observed in Purkinje cells and granular cells of the cerebellum. Intravascular globular and/or amorphous proteinaceous materials were conspicuous in capillaries and small vessels in the gray and white matters of the brain. They were positive for PAS reaction and negative for fat stain. Otherwise, no definite thrombi nor emboli were confirmed. The kidneys were in the reparative stage from foregoing acute tubular necrosis of which severity was estimsted as at most a moderate degree. The liver had moderate intracellular bile stasis with minimal liver cell necrosis and slight lymphoid cell infiltration in the portal areas. The adrenals showed slight atrophy with signs of recent regeneration. The bone marrow had diminished erythropoiesis and degeneration of megakaryocytes. The testes showed moderate atrophy with impaired spermiogenesis. The thyroid had a coincidental invasive papillary carcinoma. No marked change was observed in other organs or tissues.

Electron microscopic findings of the lung. Electron micrographs are shown in Figs. 9 and 10. Extensive loss of alveolar pneumocytes resulted in denudation of the basement membrane directly exposed to the alveolar lumina. Deposits of fine fibrillar and/or amorphous materials on the bared basement membrane were common. But the continuity of the basement membrane was mostly preserved. Pericapillary edema and an increase of collagen were found consistently in all alveolar walls, though variable in extent. Injury of capillary endothelial cells seemed to be innegligible. Fibroblastic cells were commonly seen in the alveolar walls.

\section{Discussion}

Characteristic morphological features of the paraquat lung were established by previous authors (Bullivant 1966; Toner et al. 1970; Borchard et al. 1974; Poche 
1974). When the patient survived the peracute phase of intoxication, pulmonary fibrosis of various forms and severities is inevitable. Therefore, the death is almost always attributable to respiratory failure reflecting the impairment of diffusion and/or peripheral respiratory dynamics. Although morphological features of the lung in our case were mostly similar to those in the previous reports, some were conspicuous to be mentioned.

Pulmonary lesions were corresponding to interstitial pneumonia with early but distinct fibrosis. They were diffusely distributed throughout the lungs. Thickening of the alveolar walls was derived not only from their intrinsic fibrosis but also from fusion of collapsed ones. Coexisting alveolar exudate and ultrastructurally evident interstitial edema were also confirmed. Only the initial stage of alveolar fibrosis, i.e. organization or incorporation of alveolar exudate into alveolar wall, was observed only scarcely.

The present case was in the acute stage, and extensive loss of alveolar epithelial cells without discontinuity of the basement membrane was ascertained. Regenerative proliferation of alveolar epithelial cells described in several reports including the animal experiment (Clark et al. 1966; Oreopoulos et al. 1968; Herczeg and Reif 1968; Toner et al. 1970) was not remarkable. The epithelial reparative proliferation pacing with subepithelial deposition of collagen (Bowden and Wyatt 1975) was not clearly identified, either.

Inflammatory and exudative changes of alveolar walls may possibly be attributable to the specific effect of paraquat on the alveolar walls of human lungs (Borchard et al. 1974; Poche 1974). Bowden and Wyatt (1975) pointed out the importance of vascular injury in the pathogenesis of pulmonary firosis, irrespective of the causative factors. Their view seems to be applicable, to some extent, to the pathology of our case.

TABLE 2. Pathological changes of paraquat lung in various survival periods

\begin{tabular}{|c|c|c|c|c|c|}
\hline \multirow[b]{2}{*}{ Histological change } & \multicolumn{5}{|c|}{ Survival period* } \\
\hline & $2 \operatorname{days}^{\mathrm{a}-\mathrm{cl}}$ & 4 days $^{d, e}$ & 6 days $^{f}$ & 8 daysg, h) & $\begin{array}{l}10 \text { days }^{i-m} \text { ) } \\
\text { and more }\end{array}$ \\
\hline $\begin{array}{l}\text { Capillary engorgement and } \\
\text { hemorrhage }\end{array}$ & + & + & + & + & + \\
\hline Edema and hyaline membrane & + & + & + & + & + \\
\hline Epithelial cell damage & + & + & + & $?$ & + \\
\hline $\begin{array}{l}\text { Fibrosis and fibroblastic cell } \\
\text { proliferation }\end{array}$ & & & & & \\
\hline Interstitial & & & + & + & + \\
\hline Alveolar & & & ++ & + & + \\
\hline Epithelial cell proliferation & & & & + & + \\
\hline
\end{tabular}

* Cited from the following references:

a) Hardt and Cardesa 1971; b) Yamashita et al. 1974; c) Konno and Takahashi (unpublished); d) Tilling 1968; e) Poche 1974; f) present case; g) Bullivant 1966; h) Oreopoulos et al. 1968; i) Herczeg and Reif 1968; j) Matthew et al. 1968; k) Toner et al. $1970 ; 1)$ Borchard et al. 1974 ; m) Klaff et al. 1977.

$\dagger$ Minimal . 
It is of interest to realize the consecutive histological changes of the paraquat lung in the reported cases of various survival periods (Table 2). Although the amount of poison and effects of oxygen therapy must be taken into consideration in evaluating the induced pathological changes, the critical period of pulmonary fibrosis is estimated as approximately 4 to 6 days after intoxication. In rats, Clark and his coworkers (1966) observed the interstitial fibroblastic cell proliferation evoked as early as on the 3rd day of intoxication. Exudation, interstitial or alveolar, epithelial cell damage, interstitial and alveolar fibrosis, and finally epithelial cell proliferation could be adopted as the consecutive pathological hallmarks of the paraquat lung. Of course, these are morphogenetically not inconsistent with one another. In our case, it is conspicuous to see the marked degenerative and exudative processes and pulmonary fibrosis coexisting side by side.

Indeed, some pathological aspects of the paraquat lung including interstitial and subsequent alveolar fibrosing processes may be common to other pathological conditions of known or unknown etiology (Spencer 1977). But to our surprise, fibrosis of the paraquat lung progresses too rapidly to be understood by the knowledge of general pathology.

It is noteworthy that the pulmonary lesions in paraquat poisoning are variable qualitatively as well as quantitatively. In this regard, the case of Copland and his coworkers (1974) which showed extreme alveolar fibrosis will provide a good contrast to other cases including ours.

Another conspicuous feature in the case presented in this paper was lesions of the central nervous system. The morphological change of the brain was just compatible to cerebral purpura represented by various causes including embolization and toxic agents (Colmant and Naeve 1975; Strich 1976). Symptoms possibly reflecting the lesions of the central nervous system in man as well as in animals have been described, though not frequently, in the literature (Bullivant 1966; Clark et al. 1966). But, as far as we know, the lesions pathologically documented are rare. The direct toxic effect of paraquat or its metabolites and anoxic anoxemia induced by the paraquat lung hitherto described seem to be enough for the explanation of cerebral hemorrhage. The possibility of the former is supported by the case reported by Yamashita and his coworkers (1974). It is supposed that the purpuric hemorrhage in our case may be presented by the two factors mentioned above cooperating in the fairly limited period.

The significance of the intravascular proteinaceous materials which were demonstrated anywhere in the brain without specific topographical correlations with the hemorrhagic foci was uncertain. Further study is required to elucidate the character of these materials.

Finally our case is summarized as follows: The death was mainly attributable to the impairment of respiratory function due to distinct interstitial pneumonia together with interstitial fibrosis and hyaline membrane formation. Cumulative effects by the injured liver and kidneys may have taken part in the patient's acute 
deterioration to some extent. Other than the anoxic status brought about by the diseased lung, the direct toxic effect of paraquat on blood vessels of the brain may have played a role in the development of the full blown 'purpura cerebri'.

\section{References}

1) Borchard, F., Grabensse, B., Jax, W. \& Huth, F. (1974) Morphologische Befunde bei Paraquatvergiftungen. Klin. Wschr., 52, 657-671.

2) Bowden, D.H. \& Wyatt, J.P. (1975) The lung injury and repair: A contemporary view. In: Pulmonary Pathology Decenial 1966-1975, edited by S.C. Sommers, Appleton Century Croft, New York, pp. 181-215.

3) Bullivant, C.M. (1966) Accidental poisoning by paraquat: Report of two cases in man. Brit. med. J., 1, 1272-1273.

4) Clark, D.G., McElligott, T.F. \& Weston Hurst, E. (1966) The toxicity of paraquat. Brit. J. industr. Med., 23, 126-132.

5) Colmant, H.J. \& Naeve, W. (1975) Tödliche Purpura cerebri nach kurzzeitiger Einatmung von Nitrosegasen (Nitrosegas-Vergiftung). Z. Rechtsmedizin, 76, 149-157.

6) Copland, G.M., Kolin, A. \& Shulman, H.S. (1974) Fatal pulmonary intra-alveolar fibrosis after paraquat ingestion. New Engl. J. Med., 291, 290-292.

7) von der Hardt, H. \& Cardesa, A. (1971) Die histopathologischen Frühveränderungen nach Paraquat-Intoxikation. Klin. W schr., 49, 544-550.

8) von Herczeg, E. \& Reif, A. (1968) Lungenveränderungen bei tödlich verlaufener Paraquatvergiftung. Zbl. allg. Path., 111, S. 325-328.

9) Klaff, L.J., Levin, P.J., Potgieter, P.D., Losman, J.G., Nochmovitz, L.E. \& Ferguson, A.D. (1977) Treatment of paraquat poisoning with membrane oxygenator. S. Afr. med. J., 51, 203-205.

10) Matthew, H., Logan, A., Woodruff, M.F.A. \& Heard, B. (1968) Paraquat poisoningLung transplantation. Brit. med. J., 3, 759-763.

11) Oreopoulos, D.G., Soyannwo, M.A.O., Sinniah, R., Fenton, S.S.A., MoGeown, M.G. \& Bruce, J.H. (1968) Acute renal failure in case of paraquat poisoning. Brit. med. $J ., 1,749-750$.

12) Poche, R. (1974) Die Pathogenese der Paraquat-Lunge. Pneumonologie, 150, 181-184.

13) Spencer, H. (1977) Pathology of Lung. 3rd ed., vol. 2, Pergamon Press, Oxford-LondonNew York-Paris, pp. 662-665.

14) Strich, S.J. (1976) Cerebral fat embolism. In: Greenfields' Neuropathology, edited by W. Blackwood \& J.A.N. Corsellis, Edward Arnold, Ltd., London, pp. 348-349.

15) Tilling, W. (1968) Paraquat-Intoxikation. Dtsch. med. Wschr., 50, 2439-2441.

16) Toner, P.G., Vetters, J.M., Spilg, W.G.S. \& Harland, W.A. (1970) Fine structure of the lung lesion in a case of paraquat poisoning. J. Path. Bact., 102, 182-185.

17) Yamashita, K., Aoyama, S., Ikuta, S., Miyake, T. \& Arima, K. (1974) An autopsy case of intentional poisoning by the herbicide (PARAQUAT): Comment on comparison between the injury by insecticide and herbicide. J.J.R.M., 23, 27-38. 
Fig. 3. Marked thickening of the alveolar walls due to interstitial fibrosis with cellular infiltration. Adhesion of collapsed alveolar walls may result in 'false thickening' as suggested from the picture appeared in the left lower corner. Note the alveolar exudation and hemorrhage. (Azan-Mallory $\times 95$ ).

Fig. 4. High power view of the alveolar wall. Note exudative changes, both interstitial and alveolar, and hyaline membrane formation. Plumped fibroblastic cells are seen $(\mathrm{H} \& \mathrm{E} \times 380)$.

Fig. 5. Alveolar fibrosis in the initial stage. Note fine reticular fibers adjacent to the alveolar wall concomitant with fibroblastic cell migration. These features were seen only sporadically. (reticulin stain $\times 380$ ).

Fig. 6. Hemorrhagic foci in the white matter of cerebrum. Ring or ball hemorrhage without cellular reaction. (Klüber-Barrera $\times 190$ ). 


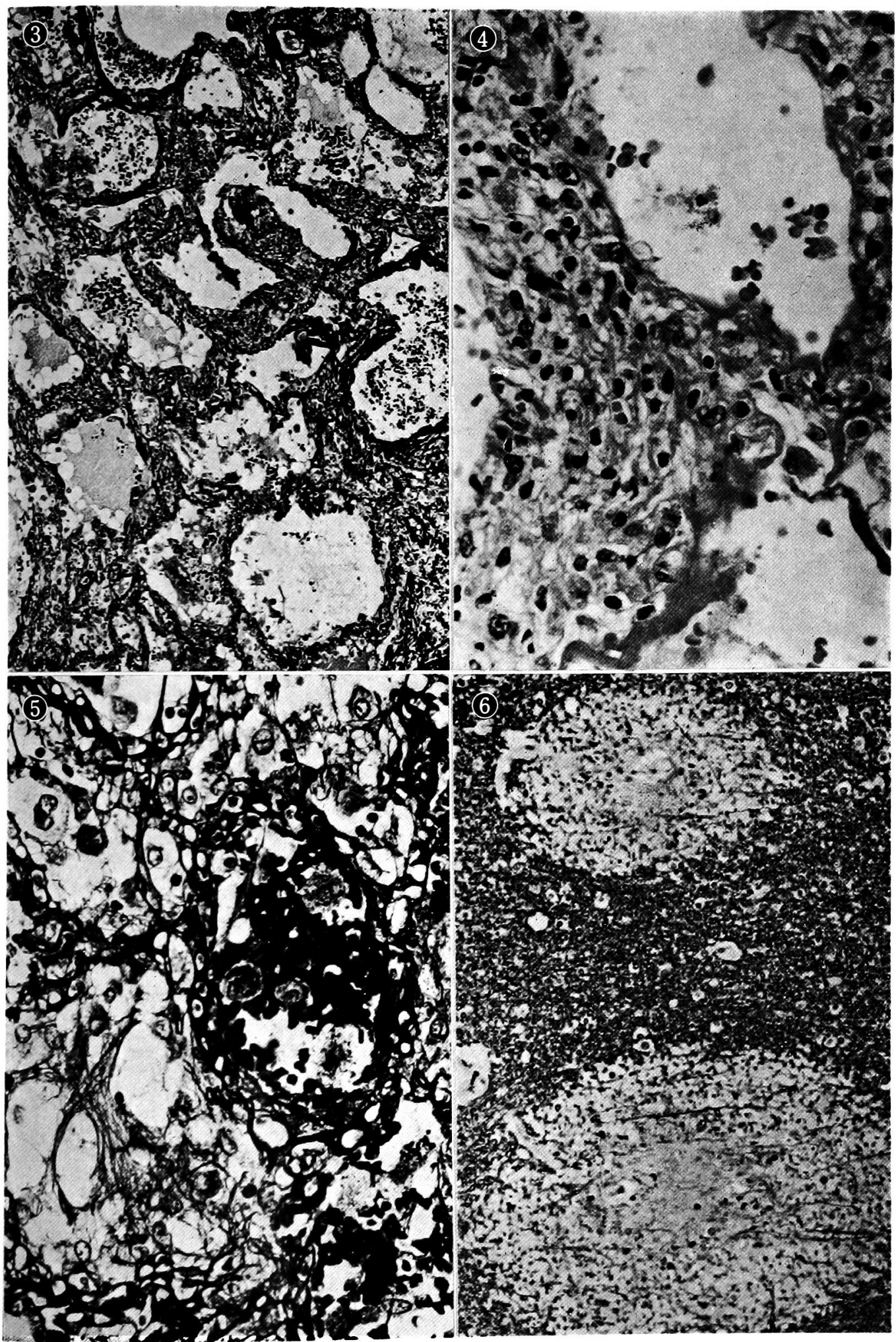


Fig. 7. Peripheral portion of a lesion of hemorrhage in the internal capsule. Shadows of extravasated erythrocytes were recognizable between the disintegrated nerve fibers (Klüber-Barrera $\times 380$ ).

Fig. 8. Proteinaceous globular and/or amorphous materials in an artery (a) and a vein (b) in the gray matter of the parietal lobe (a: H \& E $\times 380$. b: PAS $\times 190$ ).

Fig. 9. Interstitium of an alveolar wall. Note the pericapillary edema and proliferation of fine fibrils. An epithelial lining cell is detached from the basement membrane. A, alveolar air space; B, basement membrane; C, capillary endothelium; E, degenerated epithelial cell. (electron microscopy $\times \mathbf{7 , 2 0 0}$ ).

Fig. 10. Denuded epithelial basement membrane. Note the precipitation of fine fibrillar materials on the basement membrane (B). A, alveolar air space; C, capillary endothelium; F, fibrin; L, nucleus of a leukocyte. (electron microscopy $\times 12,000$ ). 

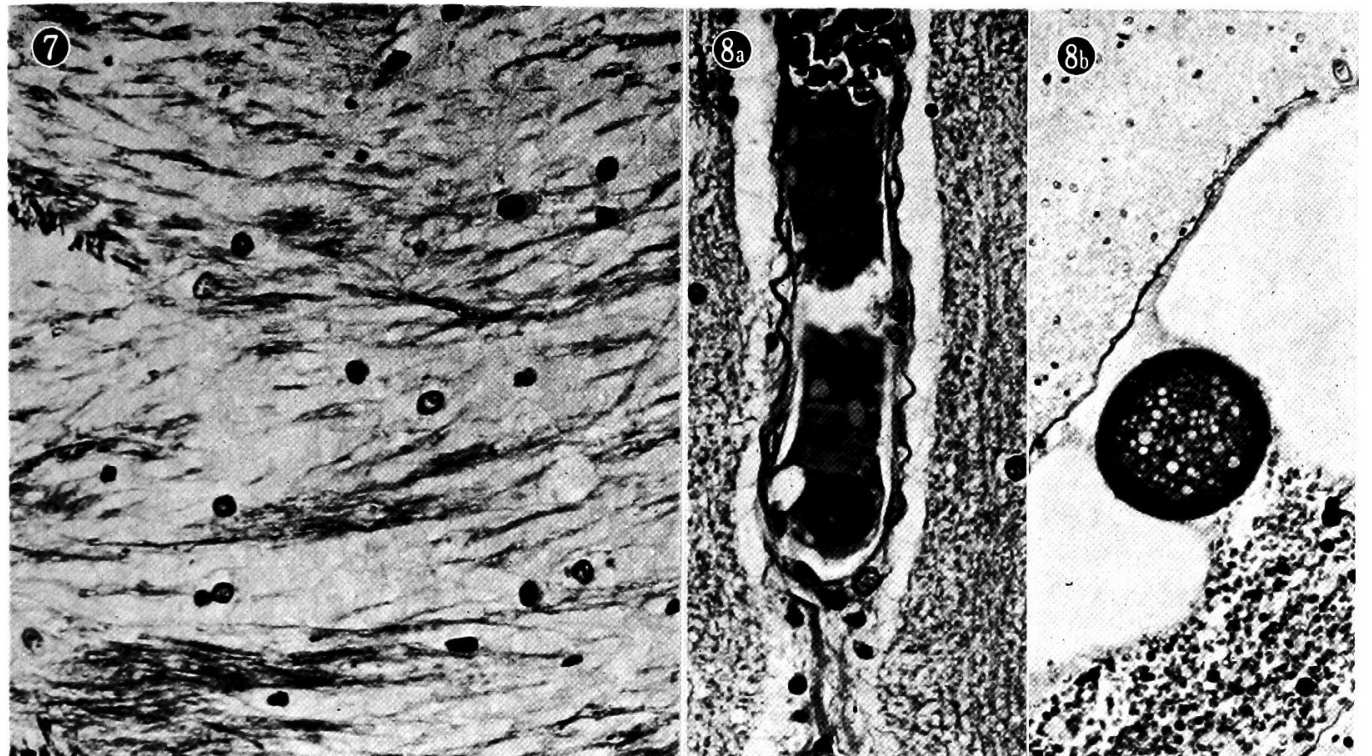

or -1 310100302

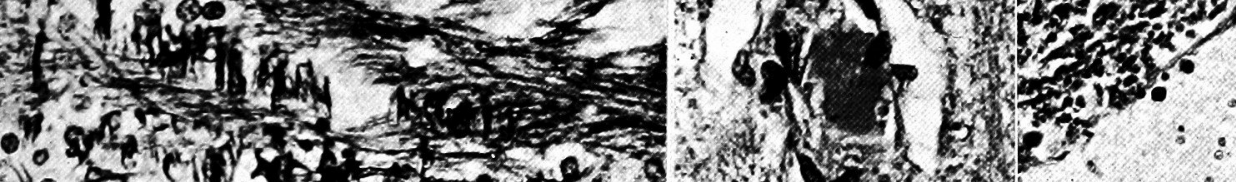

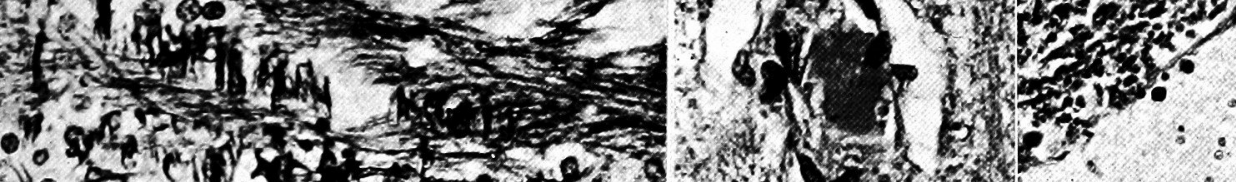

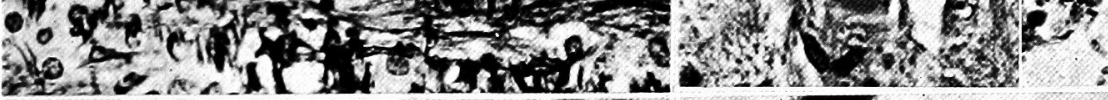
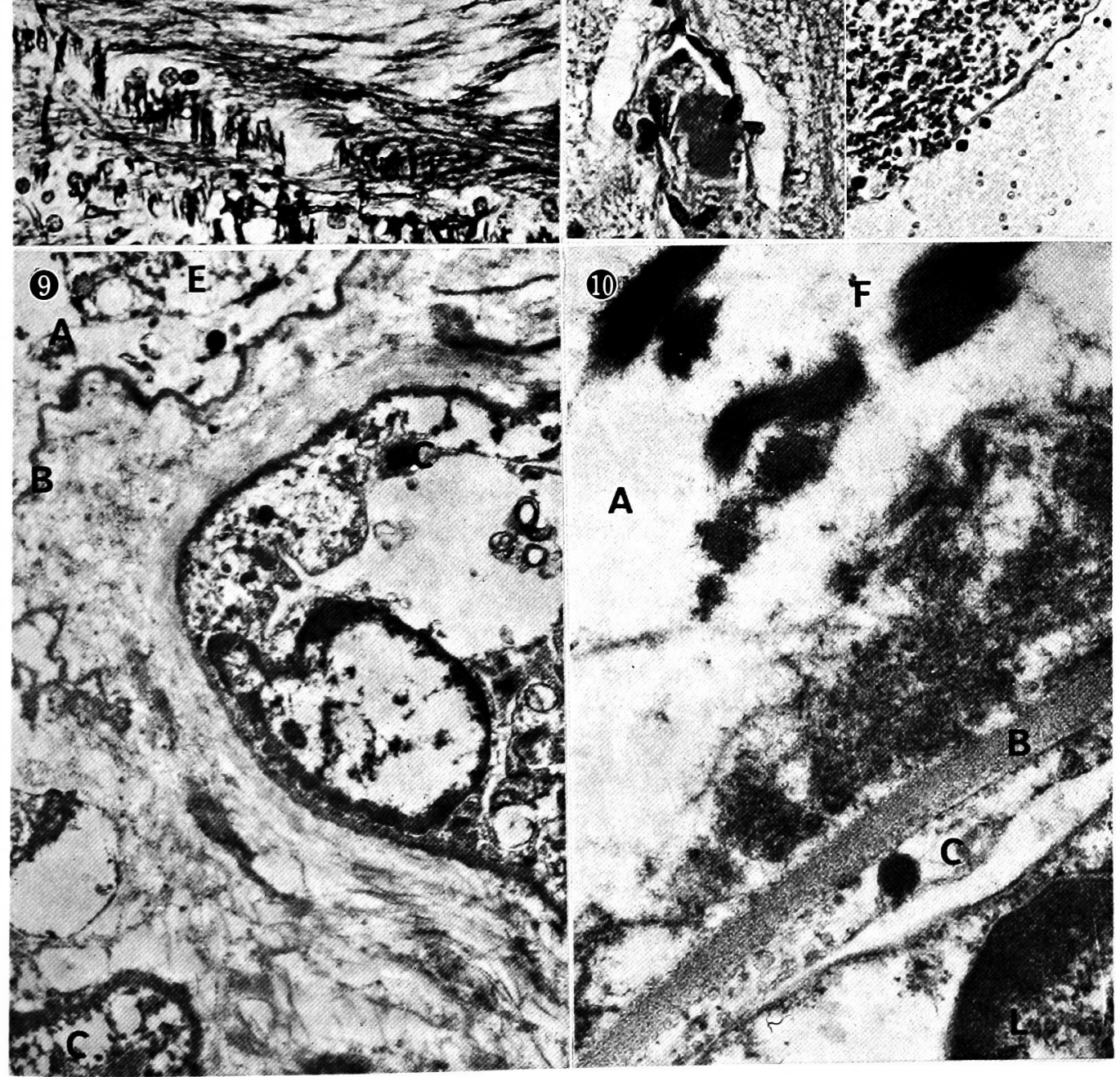